\title{
ДИНАМИКА ЭТНИЧЕСКОЙ ИДЕНТИЧНОСТИ СТУДЕНТОВ КОМИ-ПЕРМЯКОВ И РУССКИХ В ПРОЦЕССЕ ОБУЧЕНИЯ
}

\author{
Дмитрий С. Корниенко ${ }^{1,2 *}$, Игорь В. Гайдамашко \\ Сергей Л. Кандыбович 4 \\ 1 Российский университет дружбы народов, г. Москва, \\ Российская Федерачия \\ 2 Пермский государственный национальный исследовательский универ- \\ cumem, г. Пермь, Российская Федерация \\ ${ }^{3}$ Московский технологический университет, г. Москва, \\ Российская Федерачия \\ ${ }^{4}$ Научно-образовательный чентр практической психологии и психоло- \\ гической службы ФГБОУ ВО «Рязанский государственный университет \\ имени С. А. Есенина», г. Рязань, Российская Федерация \\ *E-mail: dscorney@gmail.com
}

Работа выполнена при финансовой поддержке Министерства образования и науки РФ по Программе повышения конкурентоспособности РудН «5-100» среди ведущих мировых научно-образовательных центров на 2016-2020 г2. (М.2.2.1 П 1)

В статье представлено исследование этнической идентичности и этноаффилиативных мотивов у студентов коми-пермяков и русских. Теоретикометодологическую основу составили представления об этнической идентичности Г. У. Солдатовой, Т. Г. Стефраненко и В. Ю. Хотинец. Этническая идентичность рассматривается как представления и установки индивида относительно его этнической группы. По результатам ряда работ прочесс обучения положительно сказывается на межэтническом взаимодействии, формируя взаимное принятие этносов. Проблемным вопросом для этнической идентичности коми-пермяков является усиление тенденции отхода от собственной этнической идентичности, вызванной стремлением принадлежать к более широкой или более привлекательной социальной, этнической группе. В статье рассматриваются динамика этнической идентичности у студентов коми-пермяков и русских в процессе обучения и анализ совместного влияния факторов этноса, курса обучения и пола. Выборку исследования составили студенты младших и старших курсов в количестве 273 человек. Для диагностики характеристик этнической идентичности использовалась методика - опросник «Типы этнической идентичности» (Г. У. Солдатова, С. В. Рыжова). Статистические методы: сравнительный анализ, t-критерий и дисперсионный анализ. 


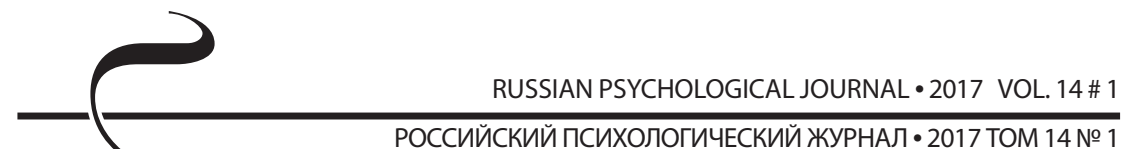

Авторами установлено, что в прочессе совместного обучения происходит снижение негативных характеристик этнической идентичности как у коми-пермяков, так и у русских студентов. Выявлено, что половые различия в этнопсихологических характеристиках проявились в том, что женщины демонстрируют более высокие показатели позитивной этнической идентичности. Результаты исследования имеют прикладное значение для формирования позитивных межэтнических отношений и идентичности.

Ключевые слова: идентичность, этническая идентичность, студенты, динамика, коми-пермяки, русские, межэтническое взаимодействие, обучение, этнос, межэтнические отношения.

Для цитирования: Корниенко Д. С., Гайдамашко И. В., Кандыбович С. Л. Динамика этнической идентичности студентов коми-пермяков и русских в процессе обучения // Российский психологический журнал. - 2017. - Т. 14. - № 1. - С. 108-123.

Материалы статьи получены 23.08.2016

UDC 159.922.4

doi: $10.21702 /$ rpj.2017.1.7

\title{
ETHNIC IDENTITY DYNAMICS IN KOMI-PERM AND RUSSIAN STUDENTS IN THE LEARNING PROCESS
}

\author{
Dmitriy S. Kornienko ${ }^{1,2^{*}}$, Igor' V. Gaidamashko ${ }^{3}$, Sergei L. Kandybovich ${ }^{4}$ \\ 'Peoples' Friendship University of Russia, Moscow, Russian Federation \\ ${ }^{2}$ Perm State National Research University, Perm, Russian Federation \\ ${ }^{3}$ Moscow Technological University, Moscow, Russian Federation \\ ${ }^{4}$ Scientific and Educational Center for Practical Psychology and Psychological \\ Service, Esenin Ryazan State University, Ryazan, Russian Federation \\ *Correspondence author. E-mail: dscorney@gmail.com
}

\section{Acknowledgments}

This study was supported by the Ministry of Education and Science of the Russian Federation under the "5-100" Program for increasing the competitiveness of the Peoples' Friendship University of Russia among leading global scientific and educational centers in 2016-2020

Ethnic identity is a system of the individual's representations and attitudes concerning his/her ethnic group. The learning process positively affects interethnic interaction and promotes the mutual acceptance of ethnic groups. The Komi-Perm people lose their ethnic identity because of the desire to belong to a wider or more 
attractive socio-ethnic group. The paper attempts the following: (a) to present the study of ethnic identity and ethnoaffiliative motives in Komi-Perm and Russian students; (b) to examine ethnic identity dynamics in Komi-Perm and Russian students in the learning process; (c) to analyze the joint effect of factors of ethnos, stage of training, and gender. Works of G. U. Soldatova, T. G. Stefanenko, and V. Yu. Khotinets in the field of ethnic identity provided the theoretical and methodological basis for this study. The participants comprised 273 junior and senior students. The "Types of Ethnic Identity" questionnaire (G. U. Soldatova, S. V. Ryzhova) was applied to examine the characteristics of ethnic identity. Statistical methods included comparative analysis, $t$-test, and variance analysis.

The study findings suggest that negative characteristics of ethnic identity decrease in Komi-Perm and Russian students in the joint learning process. Gender differences in ethnopsychological characteristics were manifested in the fact that women had higher rates of a positive ethnic identity. The results are of applied value for forming positive interethnic relations and identity.

Keywords: identity, ethnic identity, students, dynamics, Komi-Permians, Russians, interethnic interaction, learning, ethnos, interethnic relations.

For citation: Kornienko D. S., Gaidamashko I. V., Kandybovich S. L. Ethnic identity dynamics in Komi-Perm and Russian students in the learning process. Rossiiskii psikhologicheskii zhurnal - Russian Psychological Journal, 2017, V. 14, no. 1, pp. 108-123 (in Russian).

Original manuscript received 23.08.2016

\section{Введение}

Понятие «этническая идентичность» активно исследуется в социальных науках, и, в частности, в этнической и кросс-культурной психологии. Этническая идентичность является как продуктом общества, так и результатом индивидуальных психологических процессов. Социально-культурные и исторические условия создают специфический паттерн для идентификации с различными, в том числе и этническими группами. Вместе с тем, этническая идентичность обсуждается во взаимосвязи с другими идентичностями: гендерной, религиозной, социальной, национальной и др. $[3,9,19]$.

В традиционном понимании в этнопсихологии этническая идентичность является главной составляющей этнического самосознания и представляет многомерный психологический конструкт, который является результатом когнитивных и эмоциональных процессов, связанных с осознанием себя как представителя своего этноса, а также содержит в себе представления и установки относительно собственной этнической группы [6, 10, 11, 25]. 
Одной из наиболее используемых в исследованиях концепций этнической идентичности является концепция Г. У. Солдатовой и С. В. Рыжовой [10], в которой этническая идентичность рассматривается с позиции значимости этнического фактора для человека. Авторы выделяют гипо- и гиперидентичность, которые характеризуются, от минимальной до максимальной, значимостью принадлежности к этнической группе. Наиболее оптимальной при этом является «позитивная этническая идентичность», которая создает баланс между толерантностью к своей и другой этнической группе.

Важность этнической идентичности для человека связана с тем, что она является механизмом идентификации с группой, предотвращает возможные негативные последствия при отвержении другой группой и усиливает слияние со своей [21].

Возрастное развитие является тем фоном, на котором формируются содержательные представления и установки, позволяющие относить себя к тому или иному этносу [25]. Исследования динамики этнической идентичности показывают, что к юношескому возрасту усиливается межэтническое взаимодействие, повышается рефлексия межэтнического взаимодействия и увеличивается гибкость при общении с другими людьми $[4,14,17]$. Специфичным для данного возрастного периода является значимость когнитивного компонента идентичности [26] и то, что этническая идентичность встраивается в систему идентичностей человека, становясь интегрированной с другими аспектами идентичности [18, 21, 24].

Роль образования в формировании позитивных межэтнических отношений и этнической идентичности рассматривается в контексте педагогических технологий формирования толерантности и мультикультурализма [22] и программ социально-психологического сопровождения детей и подростков из семей мигрантов [2]. Наряду со специальными образовательными курсами, не менее значимым будет являться непосредственно опыт взаимодействия с представителями другой этнической группы.

Впервые вопрос об этнической идентичности коми-пермяков обсуждался в начале XX в. [20], но систематические исследования этнопсихологических особенностей коми-пермяков идут с конца 80-х гг. XX в. В целом, по результатам нескольких исследований для коми-пермяков, проживающих на территории Коми-Пермяцкого автономного округа (КПАО), характерен интенсивный процесс этнической эрозии и деэтнизации в результате социально-экономических причин $[15,16]$. Это проявляется в том, что для коми-пермяков при необходимости указать этническую принадлежность или родной язык проявляется отказ от собственной этничности в пользу более широкой социальной группы или гражданской идентичности, например, как «жители Пермского края». Также проблемой является миграция молодежи, что 
приводит к трансформации этнической идентичности в новых социальных условиях. Рассматривая данные процессы с позиции различных теорий и проведенных эмпирических исследований на других этносах, можно полагать, что процессы ассимиляции с другой группой (социальной или этнической) приводят к более благоприятной самооценке и уверенности в себе [27].

Актуальность исследований этнической идентичности связана и с социально-политическими изменениями, происходящими в обществе. Данное исследование направлено на изучение этнической идентичности студентов, представляющих доминирующий этнос и этническое меньшинство, находящихся в процессе взаимодействия. Для студентов коми-пермяков вопросы этнической идентичности актуализируются в связи с переходом в относительно новую среду, тогда как для русских студентов возникает ситуация межэтнического взаимодействия. Сравнительно мало исследований динамики этнической идентичности у этносов, находящихся в одинаковых условиях и ситуации постоянного межэтнического взаимодействия. Взаимодействию и совместному влиянию факторов этноса и пола на этнопсихологические характеристики также уделяется мало внимания. Целью данного исследования стало выявить динамику этнической идентичности у коми-пермяков и русских в процессе обучения в вузе, а также уточнить совместное влияние факторов этноса и пола на характеристики этнической идентичности. В качестве гипотез исследования выступают следующие предположения: во-первых, для коми-пермяков младших курсов будут обнаруживаться более высокие значения негативных характеристик этнической идентичности, тогда как у русских будет обнаруживаться более позитивная этническая идентичность; во-вторых, факторы этноса и курса обучения будут обнаруживать взаимодействие по показателям этнической идентичности; в-третьих, фактор пола также может являться причиной различий в характеристиках этнической идентичности и обнаруживать взаимодействие с фактором этноса.

\section{Организация и методы исследования}

Выборку составили студенты, обучающиеся по гуманитарным и техническим направлениям подготовки и специальностям в вузах Пермского края, всего 273 человека, 48\% - студенты 1 и 2 курсов (возраст M=20,13; $\mathrm{SD}=0,74)$, в дальнейшем обозначенные как «студенты младших курсов», $52 \%$ - студенты 4 и 5 курсов (возраст $M=23,3 ; S D=1,54$ ), «студенты старших курсов»; 138 человек являются коми-пермяками, 135 - русскими, 76\% - женщины. Этническая принадлежность устанавливалась по самоопределению. Этническое самоопределение на основе самоотчетов остается дискуссионным вопросом $[12,23]$, однако используется для определения этнической принадлежности в современных исследованиях $[8,13]$. Респонденты отвечали 
на вопросы о том, к какой этнической группе они себя относят и почему. В случае отнесения себя к двум и более этническим группам, а также при отсутствии ответа респонденты исключались из дальнейшего исследования. Особенностью выборки является тот факт, что студенты коми-пермяки приезжают учиться в краевой центр и переходят из группы этнического большинства в группу меньшинства, в то время как русские студенты впервые сталкиваются с ситуацией постоянного взаимодействия (в условиях совместного обучения в вузе) с представителями другого этноса.

Методики исследования. Использовался опросник «Типы этнической идентичности» (Г. У. Солдатова, С. В. Рыжова) [12], позволяющий диагностировать разные стороны этнической идентичности. Характеристики, описывающие гипоидентичность: этнонигилизм - отход от собственной этнической группы, этническая индифферентность - неопределенность в отношении этнической идентичности. Позитивная этническая идентичность описывает общее положительное отношение к своему и другим этносам и является оптимальной для полиэтнического общества. Характеристики, относящиеся к гиперидентичности: этноэгоизм - предпочтение характеристик собственного этноса другим, этноизоляционизм - убежденность в уникальности собственного этноса, и этнофанатизм - убеждение в превосходстве собственного этноса над другими. Опросник включает 30 пунктов, респондент выражает согласие с каждым утверждением, используя шкалу от 1 («не согласен») до 4 («согласен»).

Дизайн исследования. В сравнении независимых групп в качестве группирующих, независимых переменных, рассматривались: этнос (коми-пермяки и русские) и курс обучения (младшекурсники и старшекурсники), пол; в качестве зависимых переменных - показатели методик. Факторный план 2 х 2: для выявления различий и взаимодействия факторов этнос и курс обучения использовался двухфакторный дисперсионный анализ ANOVA (межгрупповой план, регрессионный подход). В связи с неравномерностью количества респондентов в различных подвыборках (например, по фактору пола) был проведен тест Левена для определения равенства дисперсий; в случае значимого результата теста дальнейший анализ проводился на основе тестов, учитывающих неравенство дисперсий. Результаты обрабатывались в программе SPSS20.

\section{Результаты и их обсуждение}

В целом по всей выборке ( $\mathrm{N}=273$ ) независимо от факторов этнической принадлежности, пола и курса обучения значения выше среднего обнаруживаются по показателям «позитивная этническая идентичность» $(\mathrm{M}=15,05$; $\mathrm{SD}=2,54)$, «этническая индифферентность» $(\mathrm{M}=11,77 ; \mathrm{SD}=2,24)$ и «этнофанатизм» $(M=10,55 ; S D=2,99)$. 
Различия в характеристиках этнической идентичности у студентов младших и старших курсов.

Между группами студентов младших и старших курсов обнаружены различия в показателях «этническая индифферентность» $(\mathrm{t}=2,78 ; \mathrm{p}<0,01)$ и «этнофанатизм» $(\mathrm{t}=4,45 ; \mathrm{p}<0,01)$ (см. таблицу 1$)$.

Таблича 1.

\section{Средние и стандартные отклонения в группах студентов младших} и старших курсов

Table 1.

Average and standard deviations for junior and senior students

\begin{tabular}{|c|c|c|c|c|}
\hline \multirow{2}{*}{$\begin{array}{c}\text { Показатели } \\
\text { Rates }\end{array}$} & \multicolumn{2}{|c|}{$\begin{array}{c}\text { Студенты младших } \\
\text { курсов } \\
\text { Junior Students } \\
(N=131) \\
\end{array}$} & \multicolumn{2}{|c|}{$\begin{array}{l}\text { Cmуденты старших курсов } \\
\text { Senior Students }(N=142)\end{array}$} \\
\hline & $\begin{array}{l}\text { Cp. ap. } \\
\text { Average }\end{array}$ & $\begin{array}{c}\text { Ст. откл. } \\
\text { Standard Deviation }\end{array}$ & $\begin{array}{l}\text { Cp. ap. } \\
\text { Average }\end{array}$ & $\begin{array}{c}\text { Ст. откл. } \\
\text { Standard Deviation }\end{array}$ \\
\hline $\begin{array}{l}\text { Этнонигилизм } \\
\text { Ethnonihilism }\end{array}$ & 7,04 & 2,48 & 6,74 & 2,10 \\
\hline $\begin{array}{c}\text { Этническая индиффе- } \\
\text { рентность } \\
\text { Ethnic indifference }\end{array}$ & 12,08 & 2,06 & 11,36 & 2,21 \\
\hline $\begin{array}{l}\text { Позитивная этниче- } \\
\text { ская идентичность } \\
\text { Positive ethnic identity }\end{array}$ & 15,04 & 2,58 & 15,15 & 2,49 \\
\hline $\begin{array}{l}\text { Этноэгоизм } \\
\text { Ethnoegoism }\end{array}$ & 8,97 & 2,45 & 8,80 & 2,65 \\
\hline $\begin{array}{l}\text { Этноизоляция } \\
\text { Ethnoisolation }\end{array}$ & 8,47 & 2,47 & 8,24 & 2,82 \\
\hline $\begin{array}{c}\text { Этнофанатизм } \\
\text { Ethnofanaticism }\end{array}$ & 11,20 & 2,79 & 9,64 & 3,00 \\
\hline
\end{tabular}

Полученные различия позволяют утверждать, что независимо от этноса в процессе обучения у студентов происходит снижение негативных проявлений этнической идентичности, но также и снижается безразличие к вопросам этнической принадлежности. Можно полагать, что студенты, обучаясь с представителями другого этноса, начинают лучше представлять собственный этнос, при этом формируя более позитивную этническую идентичность. Выявленные факты подтверждаются исследованием О. С. Саакян [9] о динамике этнической идентичности в процессе обучения: так, ею также было обнаружено увеличение показателей позитивной этнической идентичности и снижение показателей этнической индифферентности. Снижение показателей этнической 
идентичности от младшего к старшему курсу частично согласуется с данными М. Ю. Кузьмина и И. А. Конопака [7] о повышении роли этнической идентичности в юношеском возрасте. Так, в нашем исследовании студенты младших курсов демонстрируют более высокие баллы, чем старшекурсники.

Можно констатировать, что в процессе совместного обучения и межэтнического взаимодействия у студентов проявляется тенденция к формированию собственной позитивной этической идентичности; одновременно с этим вопросы этнических различий становятся менее значимыми, что совпадает с результатами М. М. Бублик и Ю. В. Севостьянова [1] об изменениях смысловой структуры этнической идентичности у людей с разным уровнем образования.

Различия в характеристиках этнической идентичности у комипермяков и русских.

При сравнении групп студентов коми-пермяков и русских вне зависимости от курса обучения были обнаружены различия в показателях «этнонигилизм» $(\mathrm{t}=1,97 ; \mathrm{p}<0,05)$ и «этноэгоизм» $(\mathrm{t}=-3,04 ; \mathrm{p}<0,01)$ (см. таблицу 2$)$.

Таблица 2.

\section{Средние и стандартные отклонения в группах студентов коми-} пермяков и русских

Table 2.

Average and standard deviations for Komi-Perm and Russian students

\begin{tabular}{|c|c|c|c|c|}
\hline \multirow{2}{*}{$\begin{array}{c}\text { Показатели } \\
\text { Rates }\end{array}$} & \multicolumn{2}{|c|}{$\begin{array}{c}\text { Коми-пермяки } \\
\text { Komi-Permians } \\
(N=138)\end{array}$} & \multicolumn{2}{|r|}{$\begin{array}{l}\text { Pусскиe } \\
\text { Russians } \\
\text { (N=135) }\end{array}$} \\
\hline & $\begin{array}{l}\text { Cp. ap. } \\
\text { Average }\end{array}$ & $\begin{array}{c}\text { Ст. откл. } \\
\text { Standard Deviation }\end{array}$ & $\begin{array}{l}\text { Cp. ap. } \\
\text { Average }\end{array}$ & $\begin{array}{c}\text { Ст. откл. } \\
\text { Standard Deviation }\end{array}$ \\
\hline $\begin{array}{c}\text { Этнонигилизм } \\
\text { Ethnonihilism }\end{array}$ & 7,15 & 2,29 & 6,61 & 2,27 \\
\hline $\begin{array}{c}\text { Этническая } \\
\text { индифферентность } \\
\text { Ethnic indifference }\end{array}$ & 11,70 & 1,86 & 11,72 & 2,44 \\
\hline $\begin{array}{l}\text { Позитивная этниче- } \\
\text { ская идентичность } \\
\text { Positive ethnic } \\
\text { identity }\end{array}$ & 15,10 & 2,44 & 15,10 & 2,63 \\
\hline $\begin{array}{l}\text { Этноэгоизм } \\
\text { Ethnoegoism }\end{array}$ & 8,42 & 2,28 & 9,35 & 2,74 \\
\hline $\begin{array}{l}\text { Этноизоляция } \\
\text { Ethnoisolation }\end{array}$ & 8,11 & 2,44 & 8,59 & 2,85 \\
\hline $\begin{array}{c}\text { Этнофанатизм } \\
\text { Ethnofanaticism }\end{array}$ & 10,30 & 2,89 & 10,47 & 3,11 \\
\hline
\end{tabular}


Полученные факты показывают, что этническая идентичность коми-пермяков отличается большим стремлением отказа от собственной этнической группы, тогда как русские демонстрируют большую центрированность на собственной группе и принадлежности к ней. Это можно объяснить тем, что студенты коми-пермяки оказываются в ситуации этнического меньшинства, и стремление влиться в другую группу приводит к размыванию их этнической идентичности. Тогда как русские студенты, оказавшись в ситуации межэтнического взаимодействия и сравнения собственной этнической группы и другой, вероятно, демонстрируют большее стремление к сохранению этнической специфичности.

Взаимодействие факторов «этнос» и «курс обучения».

В результате дисперсионного анализа было обнаружено единственное значимое взаимодействие (совместный эффект) факторов «этническая принадлежность» и «курс обучения» на переменную «этнофанатизм» $(F=4,51$, $\mathrm{p}<0,05)$. Post hoc сравнения свидетельствовали, что у русских студентов наблюдаются значимые различия в показателе «этнофанатизм» $(p<0,01)$, тогда как у коми-пермяков данный показатель значимо не меняется (таблица 3).

Таблица 3.

\section{Средние значения и стандартные отклонения показателя этнофанатизма при разных уровнях факторов «этническая принадлежность» и «курс обучения»}

Table 3.

Average and standard deviations for ethnofanaticism by the levels of "ethnos" and "stage of training"

\begin{tabular}{|l|c|c|c|c|}
\hline \multirow{2}{*}{} & \multicolumn{2}{|c|}{$\begin{array}{c}\text { Kоми-пермяки } \\
\text { Komi-Permians }\end{array}$} & \multicolumn{2}{c|}{$\begin{array}{c}\text { Pусские } \\
\text { Russians }\end{array}$} \\
\cline { 2 - 5 } & $\begin{array}{c}\text { Cp. ap. } \\
\text { Average }\end{array}$ & $\begin{array}{c}\text { Cm. omкл. } \\
\text { Standard Deviation }\end{array}$ & $\begin{array}{c}\text { Cp. ap. } \\
\text { Average }\end{array}$ & $\begin{array}{c}\text { Cm. omкл. } \\
\text { Standard Deviation }\end{array}$ \\
\hline $\begin{array}{c}\text { Студенты млад- } \\
\text { ших курсов } \\
\text { Јunior Students }\end{array}$ & 10,72 & 2,95 & 11,73 & 2,52 \\
\hline $\begin{array}{c}\text { Студенты стар- } \\
\text { ших курсов } \\
\text { Senior Students }\end{array}$ & 9,88 & 2,80 & 9,41 & 3,18 \\
\hline
\end{tabular}

Таким образом, можно сделать вывод о том, что в процессе обучения у русских и коми-пермяков снижаются показатели этнофанатизма, но при этом для русских студентов к концу обучения характерны более низкие значения, чем значения коми-пермяков. В данном случае можно ожидать, 
что именно русские студенты в процессе обучения в большей степени перестают быть центрированными на собственном этносе и готовы к принятию другой этнической группы. Возможно, что этническая принадлежность однокурсников начинает играть меньшую роль, тогда как принадлежность к общей студенческой группе - большую.

Различия между мужчинами и женщинами в характеристиках этнической идентичности.

Были обнаружены различия между мужчинами и женщинами в показателях этнопсихологических характеристик. Выявлены различия в: этнической индифферентности ( $\mathrm{t}=-2,04 ; \mathrm{p}<0,05)$, позитивной этнической идентичности $(\mathrm{t}=-3,96 ; \mathrm{p}<0,01)$, этноэгоизме $(\mathrm{t}=-2,42 ; \mathrm{p}<0,01)$, этноизоляции $(\mathrm{t}=3,15$; $\mathrm{p}<0,01)$, этнофанатизме $(\mathrm{t}=2,30 ; \mathrm{p}<0,05)$ (таблица 4).

Таблица 4.

\section{Средние и стандартные отклонения в группах мужчин и женщин}

Table 4.

Average and standard deviations for men and women

\begin{tabular}{|c|c|c|c|c|}
\hline & \multicolumn{2}{|r|}{$\begin{array}{c}\text { Мужчины } \\
\text { Men } \\
(N=66)\end{array}$} & \multicolumn{2}{|r|}{$\begin{array}{l}\text { Женщины } \\
\text { Women } \\
\text { (N=207) }\end{array}$} \\
\hline & $\begin{array}{l}\text { Cp. ap. } \\
\text { Average }\end{array}$ & $\begin{array}{c}\text { Ст. откл. } \\
\text { Standard Deviation }\end{array}$ & $\begin{array}{l}\text { Cp. ap. } \\
\text { Average }\end{array}$ & $\begin{array}{c}\text { Cт. откл. } \\
\text { Standard Deviation }\end{array}$ \\
\hline $\begin{array}{c}\text { Этнонигилизм } \\
\text { Ethnonihilism }\end{array}$ & 6,72 & 2,70 & 6,93 & 2,15 \\
\hline $\begin{array}{c}\text { Этническая } \\
\text { индифферентность } \\
\text { Ethnic indifference }\end{array}$ & 11,24 & 2,36 & 11,86 & 2,08 \\
\hline $\begin{array}{c}\text { Позитивная этниче- } \\
\text { ская идентичность } \\
\text { Positive ethnic identity }\end{array}$ & 14,05 & 3,01 & 15,43 & 2,26 \\
\hline $\begin{array}{l}\text { Этноэгоизм } \\
\text { Ethnoegoism }\end{array}$ & 9,54 & 3,02 & 8,67 & 2,36 \\
\hline $\begin{array}{l}\text { Этноизоляция } \\
\text { Ethnoisolation }\end{array}$ & 9,23 & 3,11 & 8,07 & 2,44 \\
\hline $\begin{array}{c}\text { Этнофанатизм } \\
\text { Ethnofanaticism }\end{array}$ & 11,12 & 2,90 & 10,15 & 2,99 \\
\hline
\end{tabular}

Мужчины обладают более низкими характеристиками позитивной этнической идентичности, рассматривают собственный этнос как уникальный, особенный и могут подчеркивать различия в пользу своего этноса. Полученные факты свидетельствуют о том, что мужчины придают 
большее значение этническим характеристикам, они стремятся к подчеркиванию специфических черт и принадлежности к своему этносу. Полученные данные согласуются с результатами Е. Ю. Чеботаревой [14] о большей выраженности позитивной этнической идентичности у женщин и этноизоляции у мужчин.

\section{Выводы}

Характеристики этнической идентичности меняются у студентов независимо от принадлежности к этносу. Происходит снижение негативных проявлений, таких как убежденность в превосходстве своего этноса над другими; снижаются и проявления гипоидентичности, что приводит к более четкому пониманию собственной этничности. Это свидетельствует о позитивной динамике, происходящей в отношении этноидентичности, что подтверждает первое предположение. Обучаясь с представителями другого этноса, студенты лучше понимают собственную идентичность и при этом более адекватно начинают оценивать представителей других этносов.

Вместе с тем, необходимо отметить и противоречивые особенности этнической идентичности, которые проявляются у коми-пермяков - с одной стороны, большая выраженность характеристик гиперидентичности и нетолерантность к другим людям, с другой - размывание идентичности. Вероятным объяснением данного факта является включение коми-пермяков во взаимодействие с другой этнической группой.

В динамике этнической идентичности русских происходит уменьшение такой характеристики гиперидентичности, как этнофанатизм, проявляющееся в отказе от поляризованных представлений о собственном этносе в сравнении с другими, что является позитивным для межгруппового взаимодействия и подтверждает вторую гипотезу. При этом для коми-пермяков также характерно уменьшение данной характеристики, однако для русских студентов оно носит более выраженный характер.

Также в исследовании были проанализированы половые различия в этнопсихологических характеристиках, которые проявляются в том, что мужчины обладают более выраженными характеристиками гиперидентичности и нетолерантности, что может сказываться на негативном восприятии представителей другого этноса. Полученные факты частично подтверждают третье предположение, однако можно констатировать, что фактор пола играет самостоятельную роль в формировании этнической идентичности.

Результаты данного исследования характеристик этнического самосознания имеют существенное прикладное значение для общества и формирования позитивных межэтнических отношений и идентичности. 


\section{Литература}

1. Бублик М. М., Севостьянов Ю. О. Особенности этнической идентичности молодежи в образовательной среде: психосемантический подход к исследованию // Известия волгоградского государственного педагогического университета. - 2011. - № 1 (55). - С. 119-124.

2. Ковалева Н. И. Социально-психологическое сопровождение адаптации представителей разных культуры в условиях образовательного учреждения // Культурно-историческая психология. - 2010. - № 1. - С. 75-80.

3. Кочетков В. В. Национальная и этническая идентичность в современном мире // Вестник московского университета. Серия 18: Социология и политология. - 2012. - № 2. - С. 144-162.

4. Кузьмин М. Ю. Сравнение идентичности младших школьников, подростков и лиц юношеского возраста // Сибирский психологический журнал. - 2015. - № 58. - C. 61-75. DOI: 10.17223/17267080/58/4

5. Кузьмин М. Ю., Конопак И. А. Эмпирическое изучение критериев кризиса идентичности студентов старших и младших курсов // Известия иркутского государственного университета. Серия:Психология. - 2014. - № 8. - С. 45-55.

6. Почебут Л. Г. Взаимопонимание культур. Методология и методы этнической и кросс-культурной психологии. Психология межэтнической толерантности. - СПб.: Изд-во СПбГУ, 2005. - 281 с.

7. Саакян О.С. Проблема этнической толерантности у студентов современных вузов // Российский психологический журнал. - 2013. - Т. 10. № 5. - С. 78-85.

8. Склярова Д. В. Особенности этнической идентичности студенческой молодежи кабардинской, балкарской и русской этногрупп: автореф. дисс. ... канд. психол. наук. - Ростов н/Д: Изд-во ЮФУ, 2008.

9. Смакотина Н. Л., Хвыля-Олинтер Н. А. Национально-культурная идентичность молодежи: социологический метод оценки // Вестник московского университета. Серия 18: Социология и политология. 2010. - № 2. - С. 59-79.

10. Солдатова Г. У. Межэтническое общение: когнитивная структура этнического самосознания // Познание и общение / Отв. редактор Б. Ф. Ломов. - М.: Наука, 1988. - С. 111-125.

11. Солдатова Г. У. Психология межэтнической напряженности. - М., 1998.

12. Стефаненко Т. Г. Этническая идентичность: от этнологии к социальной психологии // Вестник Московского университета. Серия 14: Психология. - 2009. - № 2. - С. 3-17.

13. Хотинец В. Ю., Мышкина С. А. Психологические особенности учебно-познавательной активности студентов разных этнических групп // Психологический журнал. - 2012. - Т. 33. - № 6. - С. 60-75. 
14. Чеботарева Е. Ю. Этническая идентичность молодежи в полиэтнической среде // Вестник российского университета дружбы народов. Серия: Психология и педагогика. - 2012. - № 1. - С. 22-28.

15. Шабаев Ю. П. Этносоциальные последствия объединения регионов (Из опыта формирования Пермского края) // Социологические исследования. - 2006. - № 3. - С. 64-71.

16. Шабаев Ю. П., Денисенко В. Н. Этносоциология в коми: становление, результаты, перспективы // Социологические исследования. - 2009. № 1. - C. 103-109.

17. Azmitia M., Syed M., Radmacher K. On the intersection of personal and social identities: Introduction and evidence from a longitudinal study of emerging adults // New directions for child and adolescent development: The intersections of personal and social identities / M. Azmitia, M. Syed, \& K. Radmacher (Eds.). - San Francisco, CA: Jossey-Bass, 2008. - V. 120. - pp. 1-16.

18. Cross W. E. The psychology of nigrescence: Revising the Cross model // Handbook of multicultural counseling / G. Ponterotto, J. M. Casas, L. A. Suzuki, \& C. M. Alexander (Eds.). - Thousand Oaks, CA: Sage, 1995. pp. 93-122.

19. Grimm J., Schmidt P., Seethaler J., Huddy L. Dynamics of National Identity: Media and Societal Factors of What We Are. - New York: Routledge, 2016. - 382 p.

20. Istomin K. V., Shabaev Y. P. Izhma Komi and Komi-Permiak: Linguistic Barriers to Geographic and Ethnic Identity // Region: Regional Studies of Russia, Eastern Europe, and Central Asia. - 2016. - V. 5. - no. 1. - pp. 53-74. DOI: 10.1353/reg.2016.0000

21. Jaspal R., Cinnirella $M$. The construction of ethnic identity: Insights from identity process theory // Ethnicities. - 2012. - pp. 503-530. DOI: $10.1177 / 1468796811432689$

22. Jovanović B., Kačapor S. Role of education in developing inter-ethnic tolerance and cooperation // Teme. - 2016. - pp. 351-364.

23. Phinney J. S. Ethnic identity in adolescents and adults: Review of research // Psychological Bulletin. - 1990. - V. 108 (3). - pp. 499-514.

24. Syed M. Developing an integrated self: Academic and ethnic identities among ethnically-diverse college students // Developmental Psychology. 2010. - no. 46. - pp. 1590-1604. doi:10.1037/a0020738

25. Umaña-Taylor A. J. et al. Ethnic and racial identity during adolescence and into young adulthood: An integrated conceptualization // Child Development. - 2014. - V. 85. - no. 1. - pp. 21-39.

26. Verkuyten M. Further Conceptualizing Ethnic and Racial Identity Research: The Social Identity Approach and Its Dynamic Model // Child Development. - 2016. (in press) 
27. Yip T., Cross W. E. A daily diary study of mental health and community involvement outcomes for three Chinese American social identities // Cultural Diversity and Ethnic Minority Psychology. - 2004. - V. 10 (4). - pp. 394-408. doi:10.1037/1099-9809.10.4.394

\section{References}

1. Bublik M. M., Sevost'yanov Yu. O. Features of young people's ethnic identity in the educational environment: a psycho-semantic approach to studying. Izvestiya volgogradskogogosudarstvennogo pedagogicheskogo universiteta-Proceedings of Volgograd State Pedagogical University, 2011, no. 1 (55), pp. 119-124 (in Russian).

2. Kovaleva N. I. Social and psychological support of the adaptation of representatives of various cultures in educational institutions. Kul'turnoistoricheskaya psikhologiya - Cultural-Historical Psychology, 2010, no. 1, pp. 75-80 (in Russian).

3. Kochetkov V. V. National and ethnic identity in the modern world. Vestnik moskovskogo universiteta - Moscow University Bulletin, Series 18: Sociology and Politology, 2012, no. 2, pp. 144-162 (in Russian).

4. Kuz'min M. Yu. A comparison of the identity of junior schoolchildren, adolescents, and young people. Sibirskii psikhologicheskii zhurnal - Siberian Psychological Journal, 2015, no. 58, pp. 61-75. DOI: 10.17223/17267080/58/4

5. Kuz'min M. Yu., Konopak I. A. The empirical study of the criteria of identity crisis in senior and junior students. Izvestiya irkutskogo gosudarstvennogo universiteta - Proceedings of Irkutsk State University. Series: Psychology, 2014, no. 8, pp. 45-55 (in Russian).

6. Pochebut L. G. Vzaimoponimanie kul'tur. Metodologiya i metody etnicheskoi i kross-kul'turnoi psikhologii. Psikhologiya mezhetnicheskoi tolerantnosti [Mutual understanding of cultures. Methodology and methods of ethnic and cross-cultural psychology. The psychology of interethnic tolerance]. St. Petersburg, St. Petersburg State University Publ., 2005. 281 p.

7. Saakyan O. S. The problem of ethnic tolerance in modern university students. Rossiiskii psikhologicheskii zhurnal - Russian Psychological Journal, 2013, V. 10, no. 5, pp. 78-85 (in Russian).

8. Sklyarova D. V. Osobennosti etnicheskoi identichnosti studencheskoi molodezhi kabardinskoi, balkarskoi i russkoi etnogrupp [Features of ethnic identity in students of Kabardian, Balkar, and Russian ethnic groups]. Diss. Cand. Sci. (Psych.). Rostov-on-Don, Southern Federal University Publ., 2008.

9. Smakotina N. L., Khvylya-Olinter N. A. National and cultural identity of young people: a sociological method of assessing. Vestnik moskovskogo universiteta - Moscow University Bulletin, Series 18: Sociology and Politology, 2010, no. 2, pp. 59-79 (in Russian). 
10. Soldatova G. U. Interethnic communication: a cognitive structure of ethnic self-consciousness. In: Poznanie i obshchenie [Cognition and communication]. Moscow, Nauka Publ., 1988, pp. 111-125.

11. Soldatova G. U. Psikhologiya mezhetnicheskoi napryazhennosti [The psychology of interethnic tension]. Moscow, 1998.

12. StefanenkoT. G. Ethnic identity: From ethnology to social psychology. Vestnik moskovskogo universiteta - Moscow University Bulletin, Series 18: Psychology, 2009, no. 2, pp. 3-17 (in Russian).

13. Khotinets V. Yu., Myshkina S. A. Psychological characteristics of the educational and cognitive activity in students of various ethnic groups. Psikhologicheskii zhurnal - Psychological Journal, 2012, V. 33, no. 6, pp. 60-75 (in Russian).

14. Chebotareva E. Yu. Young people's ethnic identity in the multiethnic environment. Vestnik rossiiskogo universiteta druzhby narodov - Bulletin of Russian Peoples' Friendship University. Series: Psychology and Pedagogy, 2012, no. 1, pp. 22-28 (in Russian).

15. Shabaev Yu. P. Ethnosocial consequences of integrating regions (the experience of forming the Perm region). Sotsiologicheskie issledovaniya - Sociological Studies, 2006, no. 3, pp. 64-71 (in Russian).

16. Shabaev Yu. P., Denisenko V. N. Ethnosociology in Komi: development, results, and prospects. Sotsiologicheskie issledovaniya - Sociological Studies, 2009, no. 1, pp. 103-109 (in Russian).

17. Azmitia M., Syed M., Radmacher K. On the intersection of personal and social identities: Introduction and evidence from a longitudinal study of emerging adults. In: Azmitia M., Syed M., \& Radmacher K. (eds.) New directions for child and adolescent development: The intersections of personal and social identities. San Francisco, CA, Jossey-Bass, 2008, V. 120, pp. 1-16.

18. Cross W. E. The psychology of nigrescence: Revising the Cross model. In: Ponterotto G., Casas J. M., Suzuki L. A., \& Alexander C. M. (eds.) Handbook of multicultural counseling. Thousand Oaks, CA, Sage, 1995, pp. 93-122.

19. Grimm J., Schmidt P., Seethaler J., Huddy L. Dynamics of National Identity: Media and Societal Factors of What We Are. New York, Routledge, 2016. 382 p.

20. Istomin K. V., Shabaev Y. P. Izhma Komi and Komi-Permiak: Linguistic Barriers to Geographic and Ethnic Identity. Region: Regional Studies of Russia, Eastern Europe, and Central Asia, 2016, V. 5, no. 1, pp. 53-74. DOI: $10.1353 / \mathrm{reg} .2016 .0000$

21. Jaspal R., Cinnirella M. The construction of ethnic identity: Insights from identity process theory. Ethnicities, 2012, pp. 503-530. DOI: $10.1177 / 1468796811432689$

22. Jovanović B., Kačapor S. Role of education in developing inter-ethnic tolerance and cooperation. Teme, 2016, pp. 351-364. 
РОССИЙСКИЙ ПСИХОЛОГИЧЕСКИЙ ЖУРНАЛ • 2017 ТОМ 14 № 1

23. Phinney J. S. Ethnic identity in adolescents and adults: Review of research. Psychological Bulletin, 1990, V. 108 (3), pp. 499-514.

24. Syed M. Developing an integrated self: Academic and ethnic identities among ethnically-diverse college students. Developmental Psychology, 2010, no. 46, pp. 1590-1604. doi:10.1037/a0020738

25. Umaña-Taylor A. J. et al. Ethnic and racial identity during adolescence and into young adulthood: An integrated conceptualization. Child Development, 2014, V. 85, no. 1, pp. 21-39.

26. Verkuyten M. Further Conceptualizing Ethnic and Racial Identity Research: The Social Identity Approach and Its Dynamic Model. Child Development, 2016. (in press)

27. Yip T., Cross W. E. A daily diary study of mental health and community involvement outcomes for three Chinese American social identities. Cultural Diversity and Ethnic Minority Psychology, 2004, V. 10 (4), pp. 394-408. doi:10.1037/1099-9809.10.4.394 